\title{
Associations of the Number of Medical Visits for the Violence Victimization and Psychological Problems in Adolescents in Korea
}

\author{
Mi-Sun Lee ${ }^{1}$ and Soo-Young Bhang ${ }^{2 凶}$ \\ ${ }^{1}$ Department of Meditation Psychology, Nungin University, Hwaseong, Republic of Korea \\ 2Department of Psychiatry, Eulji University School of Medicine, Eulji University Hospital, Seoul, Republic of Korea
}

Objective The study aimed to describe the frequency and associations of the number of medical visits for the violent victimization and mental health problems in adolescents in South Korea.

Methods In 2017, 62,276 middle and high school students participated in the thirteenth Korea Youth Risk Behavior Web-based Survey (KYRBS). The frequency of violence victimization during the last 12 months was measured. The collected data were analyzed by applying descriptive statistics, chi-square tests, multiple linear regression, and logistic regression analysis, using the SPSS 22.0. The data were weighted to generate national estimates.

Results Among the respondents (sample size $=62,276$, weighted $=3,027,488$ ), 3.7\% of boys and $1.7 \%$ of girls had experienced being treated by a doctor due to violence during the recent past 12 months. In multiple linear regression analysis, feelings of sadness or hopeless, suicide ideation, suicide plan, suicide attempt were positively associated with violence victimization $(\mathrm{F}=32656.037$, $\mathrm{p}<0.001)$ dose response.

Conclusion The results found cross-sectional evidence that violence victimization was associated with higher suicide behavior and depressed mood. The victims of violence should be referred follow-up for physical and psychological issues. Also, a policy including the first responders and medical staffs should be initiated.

Psychiatry Investig 2020;17(2):114-121

Key Words Violence, Depression, Suicide behavior, Adolescents, KYRBS.

\section{INTRODUCTION}

More than $50 \%$ of children and adolescents reported the violence experience such as physical, emotional, sexual violence or neglect in the past one year, globally. ${ }^{1}$ Between $70-80 \%$ of all boys and girls have experienced the emotional violence and prevalence rates (12-17 years) were about $50 \%$. Furthermore, among aged $8^{-11}$ years, $40 \%$ of girls and $50 \%$ of boys experienced the physical violence. ${ }^{1}$ The previous research findings of global child and adolescents (2-17 years) showed that minimum prevalence of violence experiences of $64 \%$ in Asia, 56\% in Northern America, 50\% in Africa, 34\% in Latin America and $12 \%$ in Europe. ${ }^{2}$

Received: March 13, 2019 Revised: July 11, 2019

Accepted: October 20, 2019

$\triangle$ Correspondence: Soo-Young Bhang, MD, MPH, PhD

Department of Psychiatry, Eulji University School of Medicine, Eulji University Hospital, 68 Hangeulbiseok-ro, Nowon-gu, Seoul 01830, Republic of Korea Tel: +82-2-970-8303, Fax: +82-2-970-8429, E-mail: bsy1@eulji.ac.kr

(a) This is an Open Access article distributed under the terms of the Creative Commons Attribution Non-Commercial License (https://creativecommons.org/licenses/by$\mathrm{nc} / 4.0$ ) which permits unrestricted non-commercial use, distribution, and reproduction in any medium, provided the original work is properly cited.
Children and adolescents generally visit the hospital for a variety of healthcare needs. ${ }^{3}$ Recently, many violent related victims seek medical care in the hospital. ${ }^{4}$ According to the results of the National Hospital Ambulatory Medical Care Survey (NHAMCS), the frequency of medical visit by patients younger than 19 years increased. Especially, among children, the rate of medical visits increased for using emergency department from $36.4 \%$ to $40.6 \%$ in the United States. ${ }^{3}$ In addition, $5.4 \%$ of children had an injury-related medical visit, nationally. ${ }^{5}$ People including adolescents (10 to 24 aged) accounted for more than 656,000 medical visits for injuries resulting from violence in 2008 in the US, making it a serious public health concern. ${ }^{6}$ The previous research has proved the epidemiologic and clinical factors associated with youth emergency department visits for substance abuse, and mental health in the US. In addition, the prior studies ${ }^{8-10}$ have addressed emergency department visits correlation with mental health. However, it had limitations to analyze because of focusing largely on length of stay, and hospital admission.

Adolescent experience of violent victimization is associated with depression and suicide and is a risk factor for posttrau- 
matic stress disorder (PTSD) symptoms, such as helplessness, flashbacks, intense fear, or nightmares. ${ }^{11-15}$ Research on medical visits in US found that youth were more self-injurious and violent, more likely to use drugs, and to be referred to intensive treatment. ${ }^{16}$ Nevertheless little is known about the incidence of treatment in a hospital by violence experience among adolescents in South Korea.

According to the research of 2016 KYRBS, the prevalence of violence victimization requiring medical treatment was $2.4 \%$. Also, violent victimization was significantly associated with a family environment, gender, perceived body, and academic achievement shape. ${ }^{17}$ Substantial previous work has not mainly addressed quantitative correlations related to repetitive violence victimization or the risks associated with the frequency of medical visits. However, to our knowledge, the relationship among the number of medical visits, various epidemiologic variables, and mental health problems had been not reported with nationally representative data in South Korea.

This study is aimed to identify the epidemiological characteristics of medical visits and the urgent unmet need for those exposed to violence. In addition, we aim to examine the correlation between the number of medical visit due to the violence among adolescents and mental health and evidenced basic data for preventing the re-victimization of violence.

\section{METHODS}

\section{Subjects}

Our sample consisted of the 62,276 adolescents (aged 1218 years) who participated in the 2017 Korea Youth Risk Behavior Web-based Survey (KYRBS) by the Centers for Disease Control and Prevention in South Korea. ${ }^{18}$ KYRBS is an ongoing national cross-sectional survey that assesses health-risk behaviors among middle and high school students monitor progress toward achieving national health objectives and health plan of South Korea. ${ }^{19}$ The survey has been financially supported by the National Health Promotion Fund of Korea and annually conducted with the administrative cooperation of the Korean Ministry of Education. ${ }^{19}$ In this thirteenth survey, 64,991 students from 800 schools in 400 middle schools and 400 high schools were surveyed. An anonymous self-filling online survey method, per student, was assigned to the sample classroom in the computer room of the Internet-enabled school, and randomly placed and surveyed. It informed consent was obtained from all students who participated in the survey. Finally, 62,276 students from 799 schools participated. Based on the number of students, the participation rate was $95.8 \%$. The study used deidentified data on the thirteenth KYRBS as a government-approved statistical survey (Approval number: 117058).

\section{Measurements}

The survey comprised 123 questionnaires assessing demographic characteristics and the 15 areas of health-related behaviors, including violence, suicide, and mental health. The data collected by the survey include information on responders' demographic characteristics such as sex, age, the area of residence (large city, small city, and rural), school type (middle, high, boys', girls' and coeducational school), academic achievement (high, high-middle, middle, low-middle, and low), socio-economic status (high, high-middle, middle, lowmiddle, and low), and residential type (with family, with relatives, with friend/alone/dormitory, and facility). Among the items related to mental health, the experience of being treated by a doctor due to violence, feelings of sadness or hopeless, suicide ideation, suicide plan, suicide attempt were included.

The outcome variables were assessed based on the responses to the following questions: The variable of 'medical visit' was evaluated the response to the question, 'During the recent 12 months, have you ever been treated at a hospital for violence (physical assault, intimidation, bullying, etc.) against your friends, seniors, and adults?? The response of the number of medical visit was measured using a graded categorical variable coded from 1 to 7:1 (never visited), 2 (visited 1 time), 3 (visited 2 times), 4 (visited 3 times), 5 (visited 4 times), 6 (visited 5 times), and 7 (visited 6 times over). Among the victims were further divided into two dichotomous subgroups with single versus multiple. The variable of 'depressed mood' was assessed through responses to 'During the recent 12 months, have you ever felt sad or hopeless almost every day for two weeks in a row that you stopped doing some usual activities?' The variables of 'suicide behaviors' were determined the questions, 'Have you ever seriously considered about suicide during the past 12 months?', 'Have you ever made a specific plan to commit suicide during the past 12 months?', 'Have you attempted suicide during the past 12 months?'. It was classified using a dichotomous categorical variable coded as 0 (no) or 1 (yes). ${ }^{20}$

\section{Statistical analysis}

We analyzed using descriptive statistics, chi-squared tests for categorical variables and multiple linear regression. Subgroup analysis was performed in victim group $(n=1,676)$, and logistic regression was used to test the effect of the presence of feelings of sadness or hopeless, suicide ideation, suicide plan, suicide attempt were used. SPSS Statistics 22.0 (IBM Corp., Armonk, NY, USA) was used to perform the statistical analyses. All estimates were calculated based on sample weights. As a result, 30,885 middle school respondents and 31,391 high school respondents respectively represented 1,370,462 middle school students and 1,657,026 high school students in April 2017 in South Korea. The p-value of 0.05 was set for statistical 
significance.

\section{RESULTS}

In this national-wide data, of the total 62,276 respondents, 31,624 (50.8\%) were boys, and 30,652 (49.2\%) were girls. Weights are given to represent the entire population of ages. There were 4,987 (8.1\%) and 4,392 (7.1\%) respondents aged 12 and 18, respectively, and between 1,280 and 10,874 people aged 13 to 17 . Of these, $3.7 \%$ of the boy and $1.7 \%$ of the girl aged $13-18$ were reported to have experienced being treated by a doctor due to violence during the recent past 12 months. The frequency of victimization was associated with the variables of $\operatorname{sex}\left(\chi^{2}=\right.$ $231.10, \mathrm{p}<0.001)$. The presence or absence of victimization was associated with age $\left(\chi^{2}=30.56, p<0.001\right)$. Of these, In the age group, 14 years old ( $\mathrm{n}=280,2.8 \%)$ experienced the most visits to the hospital more than once due to violence during the past one year, followed by 18 years old $(\mathrm{n}=143,3.3 \%), 13$ years old $(\mathrm{n}=244,2.5 \%), 15$ years old $(\mathrm{n}=248,2.3 \%), 17$ years old $(\mathrm{n}=$ $234,2.1 \%), 11$ years old $(\mathrm{n}=110,2.3 \%)$. On the other hands, the presence or absence of victimization was not related to the area of residence (large city, small city, rural) $\left(\chi^{2}=0.497\right.$, $\mathrm{p}>0.05)$. Additionally, the type of school $\left(\chi^{2}=16.82, \mathrm{p}<0.001\right)$, academic achievement $\left(\chi^{2}=228.39, \mathrm{p}<0.001\right)$, and socio-economic status $\left(\chi^{2}=626.66, \mathrm{p}<0.001\right)$ were related to the presence or absence of victimization. Particularly, among students with the lowest academic achievement level, victimization was $4.7 \%$ $(\mathrm{n}=293)$, followed by single visit $(\mathrm{n}=105,1.7 \%)$, second visit $(\mathrm{n}=53,0.9 \%)$, six and more visit $(\mathrm{n}=50,0.8 \%)$. In addition, in the students with the highest academic achievement level, $4.6 \%(\mathrm{n}=356)$ had experienced victimization, followed by six or more visits $(\mathrm{n}=84,1.0 \%)$, third visits $(\mathrm{n}=76,0.9 \%)$ and single visits $(\mathrm{n}=75,0.9 \%)$. The residential type was associated with the presence or absence of victimization $\left(\chi^{2}=1,869.73, p<0.001\right)$, the respondent who live with their relatives $(n=128,28.8 \%)$, followed by living in a facility $(\mathrm{n}=88,32.5 \%)$, living with friends or alone or dormitory ( $\mathrm{n}=120,5.7 \%)$ (Table 1 ).

Feelings of sadness or hopeless were related to the victimization $\left(\chi^{2}=608.73, \mathrm{p}<0.001\right)$. Suicide ideation $\left(\chi^{2}=885.01, \mathrm{p}<\right.$ $0.001)$, suicide plan $\left(\chi^{2}=1,562.69, \mathrm{p}<0.001\right)$, and suicide attempt $\left(\chi^{2}=1,325.62, p<0.001\right)$ were also associated with victimization (Table 2, Figure 1).

Factors affecting the frequency of medical visits due to violent experiences were analyzed. Before conducting the regression analysis, we checked the multicollinearity among the independent variables (feelings of sadness or hopeless, suicide ideation, suicide plan, and suicide attempt) and variance inflation factors (VIF) was 1.685. It commonly recommended that VIF values were less than 10 , so there was no multicollinearity.

Multiple regression analysis using independent variables, feelings of sadness or hopeless, suicide ideation, suicide plan, and suicide attempt factors showed that the regression model was significant $(\mathrm{F}=32,656.037, \mathrm{p}<0.001)$. The adjusted coefficient of determination $\left(\mathrm{R}^{2}\right)$ indicating the explanatory power of the model was 0.041 . The most influential factors for the medical visit were suicide plan $(0.113)$, followed by suicide attempts (0.096) (Table 3).

Compared with the single versus multiple medical visits among victimizations $(n=1,676)$ using multiple logistic regression analysis, the regression models were significant $\left(\chi^{2}=\right.$ $2,212.404, \mathrm{p}<0.001)$. Suicide attempt $(\mathrm{B}=0.687)$ was the most influential factor in medical visits. The group with multiple medical visits showed $1.989[\operatorname{Exp}(\mathrm{B})]$ times higher suicide attempt than the single visit. In addition, suicide plan $(\mathrm{B}=0.554)$ was also found to have an impact, and the relative ratio was $1.741[\operatorname{Exp}(B)]$ times higher. However, suicide ideation and feelings of sadness or hopeless did not appear to affect medical return visits (Table 4).

\section{DISCUSSION}

The purpose of this study was to investigate the epidemiologic variables related to the number of medical visits due to the violence among adolescents in South Korea and to clarify the relationship with psychopathology. To this end, we analyzed using the KYRBS of a multi-stage cluster sampling design. ${ }^{19}$

The prevalence of adolescents visiting the hospital due to violence was $2.7 \%(n=1,676$, boys $=1,158$, girls $=518)$. Compared to girls, boys frequently visited the hospital because of violent experiences. According to the sex ratios of adolescents who have had medical visits due to violence during the recent 12 months, boys were $2 \%$ higher than girls. In injury cases caused by violence against children reported in 2015 in China, boys accounted for $81.31 \%$, the boy to girl ratio was $2.22: 1 .^{21}$ The current study showed that the lowest level of academic achievement (4.7\%) among adolescents had the highest percentage of medical visits. It is similar to the finding that the adolescents with the highest or the lowest academic achievement may experience higher academic stress than those with a middle level and tend to have a higher risk of suicidal behavior. ${ }^{22}$ Also, previous studies have reported that the low SES of adolescents from multicultural families might be increased the risk of suicidal behavior. ${ }^{22,23}$ Furthermore, the previous findings reported that children with a low SES were at higher risk for psychiatric problems and violent experiences. ${ }^{24}$ However, we found that according to the number of medical visits more than six times, the ratio of medical visits when the highest SES and the lowest SES. The students of high-SES could have pressure either to maintain their excellent achievements or to catch up with peers. ${ }^{22}$ Indeed, high-SES groups may have experi- 


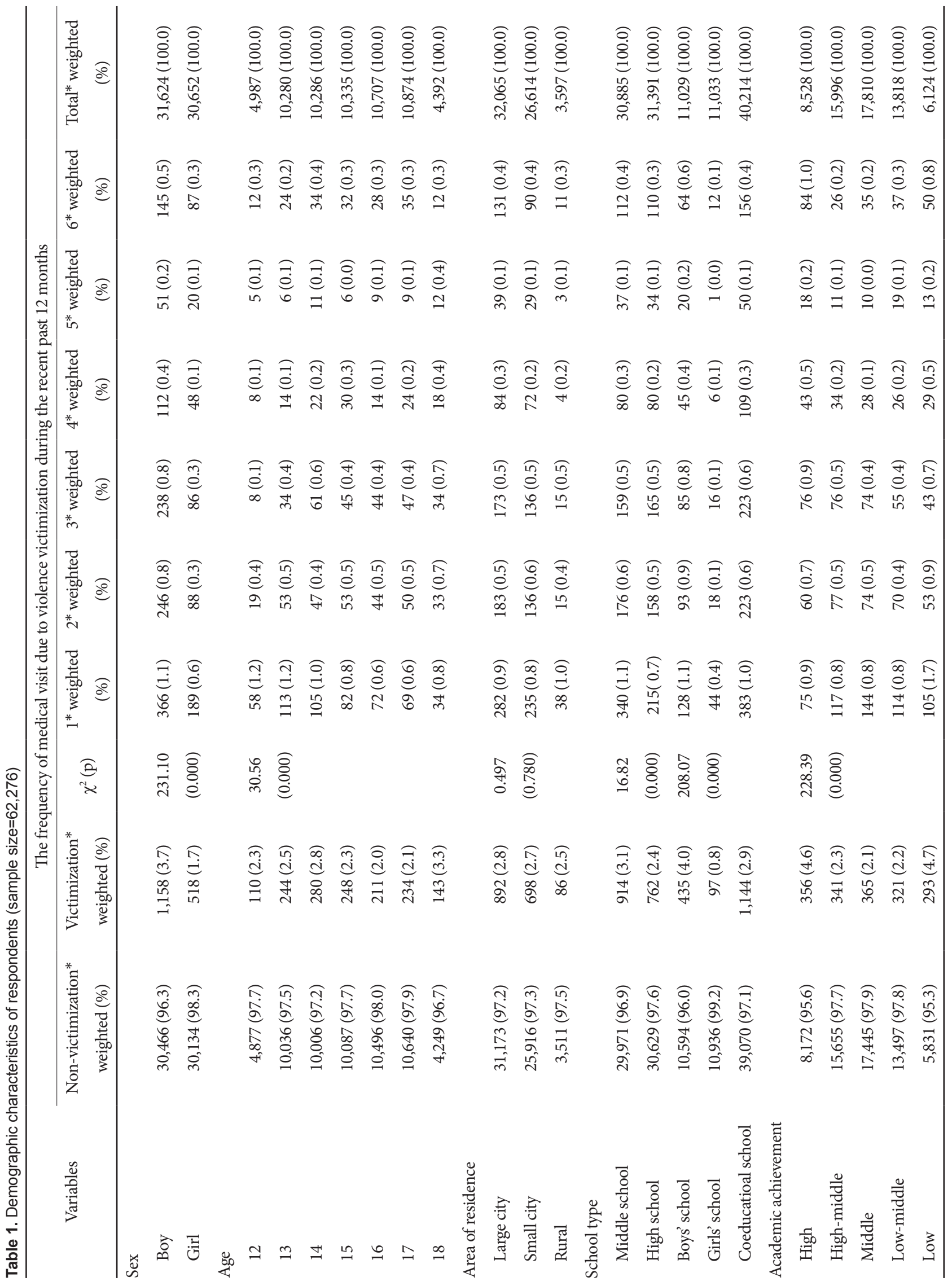




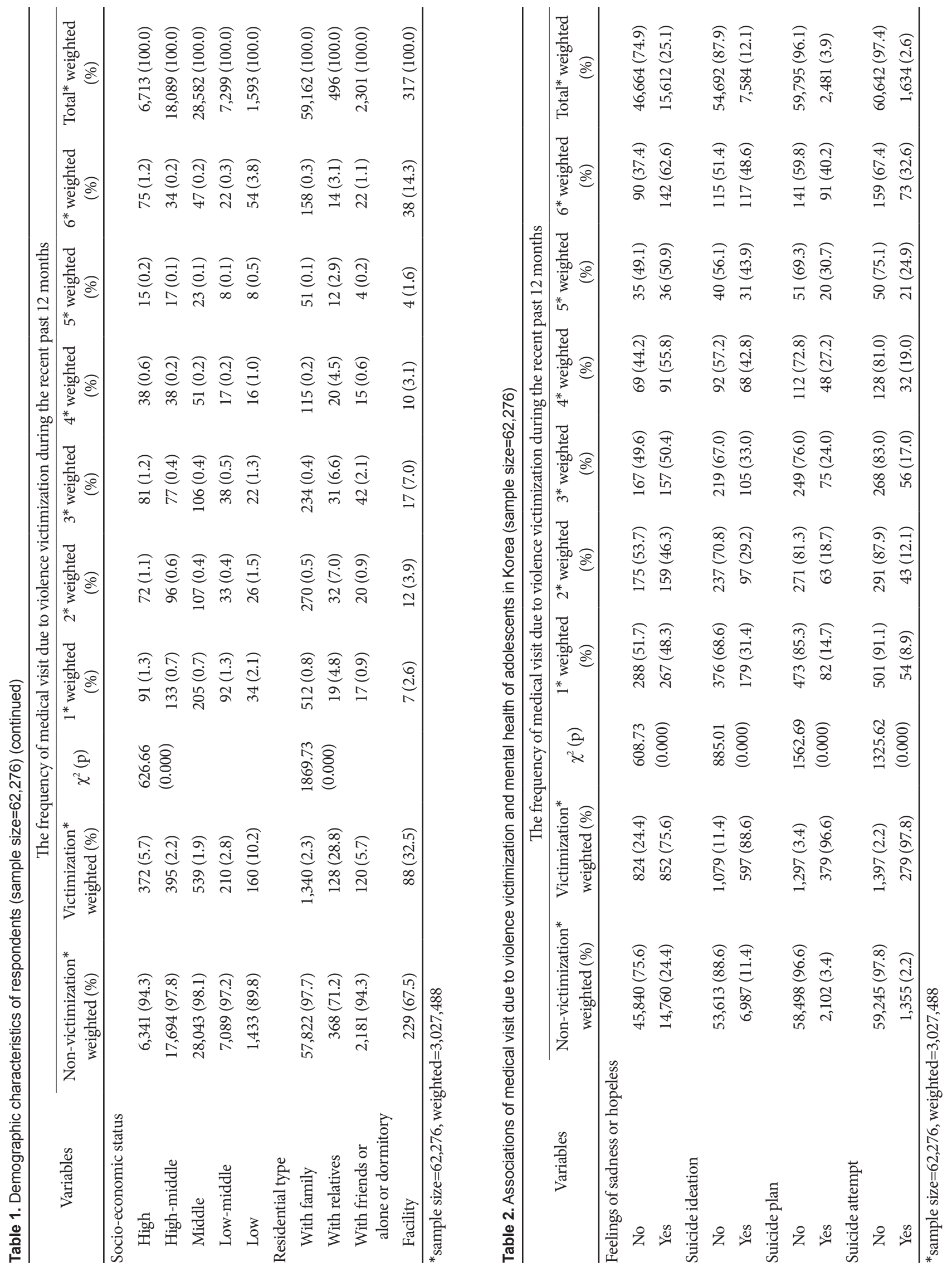


enced violence, but since they have high access to medical use, it can be assumed that the frequency of medical visits may be higher as they find the problem sooner. Therefore, we could consider protecting to preventing the violence victimization for the high-risk group and the importance of assessing risk factors.

Moreover, the current study also found that the adolescents who live with their relatives $(28.8 \%)$ or live in a facility $(32.5 \%)$ showed a higher frequency of medical visits. The results of the present study are close agreement with the results of the previous study which showed that among 1,024 Chinese students who separated from parents was higher than the students who lived with their parents. ${ }^{25}$ For adolescents living separately from their families, non-family members may be at risk for domes-

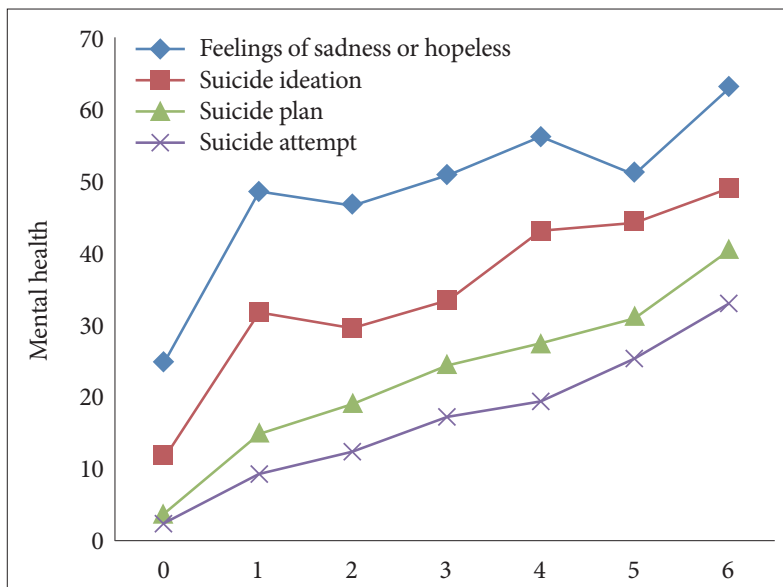

The frequency of experience of being treated by doctor due to violence

Figure 1. Associations of medical visit due to violence victimization and mental health of adolescents in Korea. tic violence, which is likely to become a perpetrator. ${ }^{26}$ In addition, they are likely to be exposed to the risk of violence because they are in an environment where they could not be protected even if there are problems at school. On the other hand, students living or living with relatives may have more emotional problems, ${ }^{27}$ which can be a factor in experiencing violence more frequently. Therefore, it is necessary to focus on therapeutic interventions and treatment for adolescents in blind spots, and countermeasures should be prepared.

The most influencing psychopathology of violence was the suicidal plan, followed by suicide attempts. It showed the similarity to the previous results that 1,718 adolescents who were involved in school bullying had significantly higher risks for suicide ideation and suicidal behavior when compared with students who were not involved in school bullying [odds ratio (OR): 1.9 and 1.9, respectively]. ${ }^{28}$ Especially, suicide plans and suicide attempts by adolescents who visited more than twice were about twice as high as those who visited a single medical visit. Especially in Korea where the suicide rate is high, the relationship between depression and suicidal behavior is highly correlated with the violence exposure of adolescents. The previous study ${ }^{29}$ had also shown negative effects on mental health as the experiences of violence in youth are repeated. These outcomes reflect issues that are a necessity to early intervene and psychoeducation preventing violence both in domestic and in school environments for students related to violence victimization and other psychological problems. ${ }^{30}$

World Health Organization recommended a public health approach to the interventions to the prevention of violence against children such as defining the problem, identifying the cause and the risk factors, designing and testing interventions

Table 3. Multiple regression of the frequency of medical visit due to violence victimization during the recent past 12 months (sample size $=62,276)$

\begin{tabular}{|c|c|c|c|c|c|c|}
\hline Independent variables & B & SE & $\beta$ & $\mathrm{t}$ & $\operatorname{Adj} R^{2}$ & $\mathrm{~F}$ \\
\hline Constant & 0.332 & 0.002 & & $155.470^{*}$ & & \\
\hline Feelings of sadness or hopeless & 0.054 & 0.001 & 0.044 & $70.876^{*}$ & & \\
\hline Suicide ideation & 0.021 & 0.001 & 0.013 & $18.369^{*}$ & 0.041 & $32656.037^{*}$ \\
\hline Suicide plan & 0.310 & 0.002 & 0.113 & $164.600^{*}$ & & \\
\hline Suicide attempt & 0.322 & 0.002 & 0.096 & $145.327^{*}$ & & \\
\hline
\end{tabular}

${ }^{*} \mathrm{p}<0.001$. Adj $\mathrm{R}^{2}$ : adjusted R squared, SE: standard error

Table 4. Multiple regression analysis of the single versus multiple medical visit (sample size $=1,676$ )

\begin{tabular}{lccccc}
\hline \multicolumn{1}{c}{ Independent variables } & $\mathrm{B}$ & $\mathrm{SE}$ & Sig. & Odd Ratio & 95\% CI \\
\hline (Constant) & 1.563 & 0.161 & $<0.001$ & 4.775 & \\
Feelings of sadness or hopeless & 0.009 & 0.118 & 0.937 & 1.009 & $0.800-1.273$ \\
Suicide ideation & 0.236 & 0.132 & 0.073 & 1.266 & $0.978-1.639$ \\
Suicide plan & 0.554 & 0.028 & $<0.001$ & 1.741 & $1.659-1.826$ \\
Suicide attempt & 0.687 & 0.033 & $<0.001$ & 1.989 & $1.881-2.102$ \\
\hline
\end{tabular}

CI: confidence interval, SE: standard error 
and increasing the effectiveness of proven interventions. ${ }^{31}$ Based on this, awareness in medical treatment and service about violence victimization would help prevent future violence. The victims of violence should be referred follow-up for physical and psychological issues. Intensive treatment such as traumafocused intervention should also be considered. Also, a systematic and structured plan should be initiated. It is necessary to find victims who have experienced violence in hospitals and schools early and to provide proper help. As a gatekeeper, an alarm system is needed to prevent a student suffering from violence at a school to avoid re-victim. From a long-term perspective, we should be aware that the adverse childhood experiences affect children to adulthood. Previous studies reported substantial consequences for that adverse childhood experiences were predictive of health anxiety in adulthood. ${ }^{32}$ The frequency of medical visits or violence victimization might be related to the personal factors, school environment, domestic environment, social factors, and overall ecosystem factors of the perpetrator or victim student. ${ }^{33}$ The future study would be needed to understand experiences of violence victimized by youth, and to develop the institutional mechanism of systematic mental health evaluation and interventions for those with severe violence exposures. ${ }^{34}$

The limitations of our study are as follows: First, in our crosssectional study design, there are limitations in explaining the causality. Second, the questionnaire on medical visits due to violence victimization was made up of only one question. Therefore, it was difficult to relate our findings regarding different settings such as in school or at home. Third, there was limited information about the personal characteristics and social variables possibly associated with traumatization. The preventive education on violence is needed constantly, and it is necessary to solve repeated psychosocial problems through prompt intervention. In addition, the interest and involvement of national and local communities, collaboration among medical professionals and mental health professionals should be steadily supported. These findings could inform the necessity of future interventions, provide the evidence of violence prevention efforts and the potential to change of national policy.

Our present study aimed to contribute to a more understanding of the relationship between medical care visit due to violence victimization and mental health among adolescents in South Korea. In finding that the epidemiologic characteristics of the subjects with a high frequency of medical visits were confirmed, and in particular, the urgent unmet need of the adolescents who visit the hospital six or more times due to violence victimization was found. As violence experiences increase, depressed mood and suicide behavior (ideation, plan, and attempt) also increase. Our findings showed that positive linear correlations between a medical visit by violence and worsen- ing of the mental health. Therefore, it is a necessity for preventing recurrence as well as the occurrence of violence. Furthermore, personal, schools, caregivers, and peers should strive to have a zero tolerance policy. Therefore, in South Korea, our research in part helps explain the high levels of violent victimization and mental health through traumatic youth experiences.

\section{Acknowledgments}

This study was supported by a grant from the Korean Mental Health Technology R\&D Project, Ministry of Health \& Welfare, Republic of Korea (HM15C1058).

\section{Conflicts of Interest}

The authors have no potential conflicts of interest to disclose.

\section{Author Contributions}

Conceptualization: Mi-Sun Lee, Soo-Young Bhang. Data curation: MiSun Lee. Formal analysis: Mi-Sun Lee, Soo-Young Bhang. Funding acquisition: Soo-Young Bhang. Investigation: Soo-Young Bhang. Methodology: Mi-Sun Lee, Soo-Young Bhang. Project administration: Soo-Young Bhang. Resources: Mi-Sun Lee, Soo-Young Bhang. Software: Mi-Sun Lee, SooYoung Bhang. Supervision: Soo-Young Bhang. Validation: Mi-Sun Lee, Soo-Young Bhang. Visualization: Mi-Sun Lee. Writing_original draft: MiSun Lee, Soo-Young Bhang. Writing-review \& editing: Mi-Sun Lee, SooYoung Bhang.

\section{ORCID iDs}

$\begin{array}{ll}\text { Mi-Sun Lee } & \text { https://orcid.org/0000-0003-2918-0546 } \\ \text { Soo-Young Bhang } & \text { https://orcid.org/0000-0001-5254-0314 }\end{array}$

\section{REFERENCES}

1. Devries K, Knight L, Petzold M, Merrill KG, Maxwell L, Williams A, et al. Who perpetrates violence against children? A systematic analysis of age-specific and sex-specific data. BMJ Paediatr Open 2018;2:e000180.

2. Hillis S, Mercy J, Amobi A, Kress H. Global prevalence of past-year violence against children: a systematic review and minimum estimates. Pediatrics 2016;137:e20154079.

3. Rasooly IR, Mullins PM, Alpern ER, Pines JM. US emergency department use by children, 2001-2010. Pediatr Emerg Care 2014;30:602-607.

4. Monuteaux MC, Fleegler EW, Lee LK. A cross-sectional study of emergency care utilization and associated costs of violent-related (assault) injuries in the United States. J Trauma Acute Care Surg 2017;83(5S Suppl 2):S240-S245.

5. Owens PL, Zodet MW, Berdahl T, Dougherty D, McCormick MC, Simpson LA. Annual report on health care for children and youth in the United States: focus on injury-related emergency department utilization and expenditures. Ambul Pediatr 2008;8:219-240.

6. Prevention CfDCa. Youth Violence: Facts at a Glance. Available at: http://www.cdc.gov/ViolencePrevention/pdf/yv-datasheeta.pdf. Accessed Feb 24, 2012.

7. Fahimi J, Aurrecoechea A, Anderson E, Herring A, Alter H. Substance abuse and mental health visits among adolescents presenting to US emergency departments. Pediatr Emerg Care 2015;31:331-338.

8. Case SD, Case BG, Olfson M, Linakis JG, Laska EM. Length of stay of pediatric mental health emergency department visits in the United States. J Am Acad Child Adolesc Psychiatry 2011;50:1110-1119.

9. Mahajan P, Alpern ER, Grupp-Phelan J, Chamberlain J, Dong L, Holubkov R, et al. Epidemiology of psychiatric-related visits to emergency departments in a multicenter collaborative research pediatric network. Pediatr Emerg Care 2009;25:715-720.

10. Santiago LI, Tunik MG, Foltin GL, Mojica MA. Children requiring 
psychiatric consultation in the pediatric emergency department: epidemiology, resource utilization, and complications. Pediatr Emerg Care 2006;22:85-89.

11. Ziegenhain U, Kunster AK, Besier T. Violence against children. Bundesgesundheitsblatt Gesundheitsforschung Gesundheitsschutz 2016;59:44-51.

12. Bauer NS, Herrenkohl TI, Lozano P, Rivara FP, Hill KG, Hawkins JD. Childhood bullying involvement and exposure to intimate partner violence. Pediatrics 2006;118:e235-e242.

13. Idsoe T, Dyregrov A, Idsoe EC. Bullying and PTSD symptoms. J Abnorm Child Psychol 2012;40:901-911.

14. Kaltiala-Heino R, Rimpela M, Marttunen M, Rimpela A, Rantanen P. Bullying, depression, and suicidal ideation in Finnish adolescents: school survey. BMJ 1999;319:348-351.

15. Kharasch SJ, Yuknek J, Vinci RJ, Herbert B, Zuckerman B. Violence-related injuries in a pediatric emergency department. Pediatr Emerg Care 1997;13:95-97.

16. Evans ME, Boothroyd RA. A comparison of youth referred to psychiatric emergency services: police versus other sources. J Am Acad Psychiatry Law 2002;30:74-80.

17. Park S, Lee Y, Jang H, Jo M. Violence victimization in Korean adolescents: risk factors and psychological problems. Int J Environ Res Public Health 2017;14. pii: E541.

18. Prevention KCfDCa. The Thirteenth Korea Youth Risk Behavior WebBased Survey. Cheongwon: Korea Centers for Disease Control and Prevention; 2017.

19. Kim Y, Choi S, Chun C, Park S, Khang YH, Oh K. Data Resource Profile: The Korea Youth Risk Behavior Web-based Survey (KYRBS). Int J Epidemiol 2016;45:1076-1076e.

20. Lee KJ. Current smoking and secondhand smoke exposure and depression among Korean adolescents: analysis of a national cross-sectional survey. BMJ Open 2014;4:e003734.

21. Yang L, Gao X, Jin Y, Ye PP, Wang Y, Deng X, et al. Current status and change trend of violence against children in China from 2006 to 2015, an analysis on data from National Injury Surveillance System. Zhonghua Liu Xing Bing Xue Za Zhi 2017;38:1222-1225.

22. Park S, Lee Y. Factors that affect suicide attempts of adolescents in multicultural families in Korea. Int J Environ Res Public Health 2016;13. pii: E1184.

23. Kang EH, Hyun MK, Choi SM, Kim JM, Kim GM, Woo JM. Twelve- month prevalence and predictors of self-reported suicidal ideation and suicide attempt among Korean adolescents in a web-based nationwide survey. Aust N Z J Psychiatry 2015;49:47-53.

24. Heshmat R, Qorbani M, Ghoreshi B, Djalalinia S, Tabatabaie OR, Safiri S, et al. Association of socioeconomic status with psychiatric problems and violent behaviours in a nationally representative sample of Iranian children and adolescents: the CASPIAN-IV study. BMJ Open 2016;6:e 011615.

25. Zhang Q, Meng Y, Wu L, Yao R, Fu L. Association of aggressive behavior with separation from parents and social anxiety in grade four to six of rural senior primary school students in Anhui Province in 2014. Wei Sheng Yan Jiu 2018;47:206-217.

26. Farrell PC, Negin J, Houasia P, Munamua AB, Leon DP, Rimon M, et al. Hospital visits due to domestic violence from 1994 to 2011 in the Solomon Islands: a descriptive case series. Hawaii J Med Public Health 2014;73:276-282.

27. Man Y, Mengmeng L, Lezhi L, Ting M, Jingping Z. The psychological problems and related influential factors of left-behind adolescents (LBA) in Hunan, China: a cross sectional study. Int J Equity Health 2017;16:163.

28. Kim YS, Koh YJ, Leventhal B. School bullying and suicidal risk in Korean middle school students. Pediatrics 2005;115:357-363.

29. Kwon H, Lee JS, Kim AR, Hong HJ, Kweon YS. Risk Factors for Suicidal Ideation and Attempts in Adolescents. J Korean Acad Child Adolesc Psychiatry 2018;29:114-121.

30. Volkl-Kernstock S, Huemer J, Jandl-Jager E, Abensberg-Traun M, Marecek S, Pellegrini E, et al. Experiences of domestic and school violence among child and adolescent psychiatric outpatients. Child Psychiatry Hum Dev 2016;47:691-695.

31. Organization WH. World Report on Violence and Health. Geneva: World Health Organization; 2002.

32. Flynn-O'Brien KT, Rivara FP, Weiss NS, Lea VA, Marcelin LH, Vertefeuille J, et al. Prevalence of physical violence against children in Haiti: a national population-based cross-sectional survey. Child Abuse Negl 2016;51:154-162.

33. Usta J, Taleb R. Addressing domestic violence in primary care: what the physician needs to know. Libyan J Med 2014;9:23527.

34. Clarke K, Patalay P, Allen E, Knight L, Naker D, Devries K. Patterns and predictors of violence against children in Uganda: a latent class analysis. BMJ Open 2016;6:e010443. 